\title{
Leslie G. Ungerleider (1946-2020): the multiple careers of a single extraordinary scientist
}

\author{
Leslie Gail Ungerleider, a distinguished experimental psychologist and neuroscientist, previously Chief of the \\ Laboratory of Brain and Cognition at the National Institute of Mental Health, died suddenly on 11 December 2020. \\ Friends, family, colleagues, and trainees all the world over mourn her passing, but also celebrate her life and \\ extraordinary achievements.
}

r. Leslie Ungerleider's career took the shape of an apeirogon, a generalized polygon with a seemingly infinite number of sides. With uniform brilliance, she tackled a wide range of topics with an even wider range of methodologies. She was the consummate scientist, executing studies with precision and finesse at the pinnacle of the field of cognitive neuroscience, and she ventured where few women had gone before her. Dr. Ungerleider's contributions will continue to reverberate throughout the field and her impact will be felt for generations to come. Her wisdom, mentorship, and generosity of spirit will be sorely missed by her colleagues, collaborators, peers, and trainees.

Dr. Leslie Ungerleider, the daughter of Albert and Frieda (Mandel) Cohen, was born on 17 April 1946 in New York City. An academically bright and motivated student, she completed high school at age 16 and received a B.A. magna cum laude in psychology in 1966 at State University of New York (SUNY) Binghamton and a Ph.D. in experimental psychology from New York University in 1970. Prior to completing a postdoc at Stanford University in 1975, she taught at the University of Oklahoma. A chance meeting with Mortimer Mishkin from the National Institute of Mental Health, who would become a key collaborator, convinced her to do a second postdoc at the National Institutes of Health (NIH). She agreed and subsequently ascended the NIH ranks, co-founding and serving as the Chief of the Laboratory of Brain and Cognition and as a designated NIH Distinguished Investigator from 2008 onwards.

In recognition of her numerous contributions to the field and in advancing our understanding of brain function and the translational health ramifications, Dr. Ungerleider has received virtually all of the most prestigious accolades, including membership in the National Academy of Sciences, the Institute of Medicine of the National Academies, and the American Academy of Arts and Sciences. She was the recipient of the Women in Neuroscience

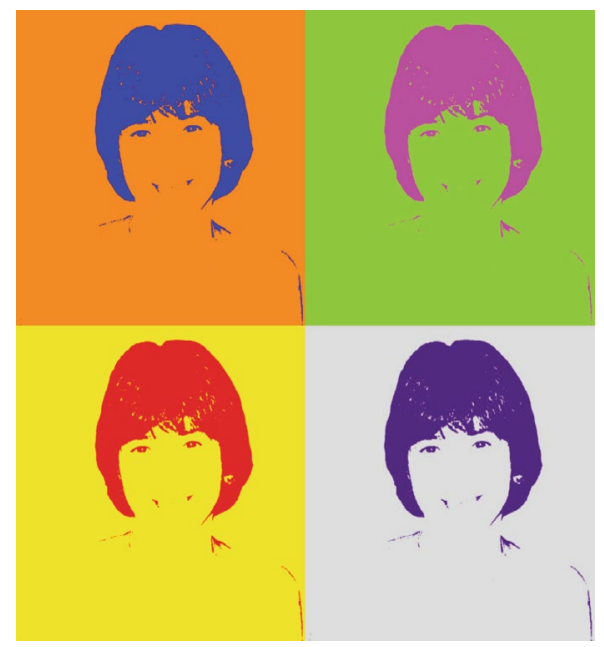

Credit: Original photo by Michael Beauchamp, adapted by Marlene Behrmann

Mika Salpeter Lifetime Achievement Award from the Society for Neuroscience, the University of Louisville Grawemeyer Award, and the Association of Psychological Science William James Fellow Award, to name but a few. Very few scientists, and extremely few women, have attained such stature in the field of neuroscience. A short anecdote, relayed by Alex Martin from NIH, illustrates how rare it was to have a woman amongst the most senior investigators. Her productivity was so extensive and senior women so scarce that, at the Society for Neuroscience meeting a number of years ago, when Dr. Ungerleider ascended to the podium for her talk, a young woman in front of Martin turned to a second woman and said, clearly startled, "I thought Leslie Ungerleider was a man.” In large part, because of Dr. Ungerleider's sacrifices, commitment, and renown, this kind of error will become increasingly less common in future.

Dr. Ungerleider may be especially well known for the neurobehavioral discovery of the 'two cortical visual systems', one ventral and specialized for object recognition and the other dorsal and specialized for visuospatial perception, from work performed jointly with Mishkin. Although this result still holds sway 40 years later, this one finding belies the enormous number of other intellectual contributions Dr. Ungerleider made over the years. Furthermore, as the methodological progress of the field advanced, so did she; moreover, she was often at the driving forefront of these innovative developments. She was a fervent adopter of evolving technologies and considered these as game-changers that ought to be embraced.

Dr. Ungerleider traversed the field of neuroscience, from her first study on heterosynaptic and homosynaptic mechanisms of summation in rats, published in Science in 1970 (https://doi.org/10.1126/science.169. 3947.785), through to a 2020 study showing a double dissociation of cortical areas for processing facial expression versus head orientation using fMRI in macaques (https:// doi.org/10.1523/jneurosci.0524-20.2020). By then, she had also ventured all the way up to humans and all the way anteriorly to prefrontal cortex, uncovering feedback from the frontal eye field and dorsolateral prefrontal cortex to primary visual cortex in the service of awareness-dependent figureground segregation (https://doi.org/10.1073/ pnas.1922832117). Along her scientific journey, she conducted studies of plasticity following retinal laser lesions and studies of inferotemporal cortex function after amygdala lesions, as well as detailed anatomical investigations of subcortical projections from middle temporal area and of the inferior longitudinal fasciculus. Lest any domain remain untouched by Dr. Ungerleider's hands, her prowess with tracer studies, with single-unit neurophysiology investigations, and with PET neuroimaging round out her many scientific contributions. The breadth and depth of Dr. Ungerleider's science is astonishing and is reflected by an $h$-index of 110 and a citation count of 70,000.

Remarkably, while conducting this cutting-edge science, Dr. Ungerleider found time to nurture trainees, including post-baccalaureate and postdoctoral fellows and junior scientists, while maintaining 
strong relationships with previous trainees scattered all over the world. From the outpouring of condolences on Dr. Ungerleider's passing (https://www. kudoboard.com/boards/xTXTsGrh), it is clear that, notwithstanding her diminutive physical stature, Dr. Ungerleider was both enormously terrifying and immensely supportive. She demanded the best from those in her lab and she always gave them her best in return.

In an interview with Aina Puce in mid-2020 after receiving the Glass Brain Award (https://www.youtube.com/ watch? $\mathrm{v}=\mathrm{zt} 4 \mathrm{i} 71 \mathrm{bXrcw})$, Dr. Ungerleider stated that her career comprised one happy accident after another. Statistically, this seems highly improbable, and her trajectory was more likely the outcome of smart decisions at the many choice points along the way. In addition to her scientific contributions, she leaves a field widely seeded by her academic offspring-she has 52 direct descendants on Neurotree and these descendants have 101 of their own descendants. And through her mentoring, she instilled in all a 'what does it mean?' ethos, pushing for the interpretation, the story, the theory, and the explanation rather than the empirical findings alone. Last, in the 2020 interview mentioned above, she left a message to young scientists, especially women scientists, to accept all invitations even if terrified, to tell the world about your science even if it initially goes against your natural grain, and to stay and continue to contribute to science.
I am especially grateful to have had the opportunity to collaborate with Dr. Ungerleider . It was my singular pleasure to work with and be inspired by her. I only wish that I, and others in the field, had had more time to benefit from her wisdom and grace. The ripple effect of her multiple careers will impact neuroscience for a long time to come.

Marlene Behrmann

Department of Psychology and Neuroscience Institute, Carnegie Mellon University, Pittsburgh, Pennsylvania, USA.

$\bigotimes_{\mathcal{e} \text {-mail:behrmann@cmu.edu }}$

Published online: 4 February 2021 https://doi.org/10.1038/s41593-021-00808-6 